\title{
ALTERNATIVE BINDERS TO BENTONITE FOR IRON ORE PELLETIZING - PART I: EFFECTS ON PHYSICAL AND MECHANICAL PROPERTIES
}

\author{
O. SIVRIKAYA ${ }^{1}$ and A.I. AROL ${ }^{2}$ \\ ${ }^{1}$ Adana Science and Technology University, Faculty of Engineering and Natural Sciences, Dept. of Mining and \\ Mineral Processing Eng., 01180, Adana, Turkey, osmansivrikaya@gmail.com \\ ${ }^{2}$ Middle East Technical University, Mining Engineering Department, Ankara, Turkey, arol@metu.edu.tr
}

Artigo submetido em novembro/2013 e aceito em março/2014

DOI: http://dx.doi.org/10.15628/holos.2014.1758

\begin{abstract}
The use of conventional bentonite binder is favorable in terms of mechanical and metallurgical pellet properties, however, because of its acid constituents bentonite is considered as impurity especially for iron ores with high acidic content. Therefore, alternative binders to bentonite have been tested. Organic binders are the most studied binders and they yield pellets with good wet strength; they fail in terms of preheated and fired pellet strengths. This study was conducted to investigate how insufficient pellet strengths can be improved when organic binders are used as binder. The addition of a lowmelting temperature and slag bonding/strength increasing constituent (free in acidic contents) into pellet feed was proposed. Addition of boron compounds such as colemanite, tincal, borax pentahydrate, boric acid together with organic binders such as CMC, starch, dextrin and some organic based binders, into iron oxide pellet was tested. Wet and thermally treated pellet physical-mechanical qualities (balling - moisture content
\end{abstract}

- size - shape - drop number - compressive strengths porosity - dustiness) were determined. The results showed that good quality wet, dry, preheated and fired pellets can be produced with combined binders (an organic binder plus a boron compound) when compared with bentonite-bonded pellets. While organic binders provided sufficient wet and dry pellet strengths, the boron compounds provided the required preheated and fired pellet strengths at even lower firing temperature. Especially, the contribution of boron compound addition is most pronounced for hematite pellets which do not have strengthening mechanism through oxidation like magnetite pellets during firing. Therefore, addition of boron compound is beneficial to recover the low physicalmechanical qualities of pellets produced with organic binders through slag bonding mechanism. Furthermore, lowering the firing temperature thanks to low-melting boron compounds will be cost-effective for firing part of the pelletizing plants.

KEYWORDS: iron ore pelletizing, bentonite \& organic binder, boron compounds, colemanite, physical and mechanical properties.. 


\section{INTRODUCTION}

The main raw material for iron-steel industry is natural iron oxide ores. Natural iron oxide ores can be typically classified as high grade ( $>65 \% \mathrm{Fe}$ ), medium grade $(<65$ and $>62 \% \mathrm{Fe}$ ) and low grade $(<62 \% \mathrm{Fe})$ in terms of their Fe grades. High grade massive lump iron oxides (i.e. crushed and sized ore) which can directly be used in the iron-steel facilities to produce metallic iron are not abundant in earth's crust to supply the increasing consumption of iron-steel industry. The exploitation of medium and low grade iron ores is possible after enrichment. Low grade iron ores such as magnetite and hematite with impurity gangue minerals containing e.g. $\mathrm{Si}, \mathrm{Al}, \mathrm{Ca}, \mathrm{Mg}, \mathrm{Na}$, $\mathrm{K}, \mathrm{P}$ and $\mathrm{S}$ compounds have to be upgraded to an acceptable sufficient level of iron grade. This type low grade iron ores require concentration before use. During concentration (removal of impurities), iron ores are crushed and ground to achieve liberation before the implementation of separation techniques. Liberation can mostly be achieved at a very fine particle size. Grinding and liberation process leaves the iron ore in a finely ground state (e.g. 100\% minus $106 \mu \mathrm{m}$ or generally $80 \%$ minus $44 \mu \mathrm{m}$ ) that is not easily transported or readily processed in iron-steel making facilities. The separation techniques are mainly magnetic separation due to magnetic susceptibility of iron ores or flotation since it is efficiently applied to fine size particles. After removal of impurities, concentrates with sufficient iron grade are obtained, however, this time the concentrate obtained is not suitable to be charged directly into the iron-making processes such as the blast furnace or the DR-plant without converting it into suitably sized agglomerates. Hence, an agglomeration technique should be applied to fine concentrates. The most commonly applied one is pelletizing in iron ore industry. Originally the pelletizing process was developed in the USA to treat the ultra-fine mineral dressing products obtained from the upgrading of Mesabi ore and has been utilized to provide a blast furnace feed product with Fe grade of about 65\% (Ball et al., 1973). In pelletizing, iron ore, water and a binder are balled in a mechanical disc or drum to produce wet pellets.

Bentonite is the most widely used binder in iron ore pelletizing industry. The use of bentonite is favorable in terms of physical, mechanical and metallurgical pellet properties, however, because of its acid constituents $\left(\mathrm{SiO}_{2}\right.$ and $\left.\mathrm{Al}_{2} \mathrm{O}_{3}\right)$ it is considered as a chemical impurity especially for concentrate with high acidic content. This has prompted long-term interest in developing or discovering binders free in silica. Therefore, alternative binders to bentonite have been tested for many years. Because of good binding properties without contaminating the product pellets, organic binders have attracted attention among researchers (Eisele and Kawatra, 2003, Sivrikaya, 2011). Organic binders provided good wet pellet strength; however, they have found limited application in industry. Ripke and Kawatra (2000) gave a statistic about the pellet plants in USA. Eight of the nine plants utilized bentonite as binder, while the ninth plant used organic binder. The reason behind the failure of organic binders in industry is their low burning temperatures. Organic binders which burnt out at relatively low temperatures $\left(<250^{\circ} \mathrm{C}\right)$ with virtually no or little residue can not provide bonding to iron oxide grains at higher firing temperatures. In literature, the results showed that organic binders produce good quality wet and dry pellets. However, they fail to impart enough strength to the preheated and fired pellets as a result of reduced slag bonding (Kater and Steeghs1984, Goetzman et al., 1988, Sivrikaya, 2011) which is especially more important in hematite ore pelletizing due to lack of oxide bonding. As such, organic binders have hitherto failed to be an alternative to bentonite, except a few cases of 
straight-grate pelletizing operation, where there is no dynamic pellet bed. In recent years efforts have been focused on improving the preheated and fired strength of pellets produced with organic binders. In this context, boron compounds have been considered as an additive in conjunction with organic binders (Sivrikaya, 2011). A few researchers have investigated the use of boron compounds in iron ore agglomeration and found promising results (Köroğlu, 1980, Timuçin et al., 1986, Malysheva et al., 1996, Schmitt, 2005, Akberdin and Kim 2008)

This study was conducted to investigate how insufficient preheated and fired pellet strengths can be improved when organic binders are used as binder. Boron compounds with lowmelting temperature and free of silica and alumina are thought to be a potential solution to overcome the lack of slag forming constituents encountered with organic binders as they are known for their low melting temperatures. Addition of a slag bonding/strength increasing constituent into pellet feed to provide pellet strength with the use of organic binders was proposed.

In this part of the study, the effects on addition of boron compounds such as colemanite, tincal, borax pentahydrate, boric acid together with organic binders such as $\mathrm{CMC}$, starch, dextrin and some organic based binders (OBB), into magnetite and hematite pellet mixture was studied on pellet physical-mechanical properties. Wet and thermally treated pellet physical-mechanical qualities (balling characteristic - moisture content - size - shape - drop number - compressive strengths - porosity - dustiness) were determined and presented.

\section{MATERIALS AND METHODS}

\subsection{Raw Materials}

Two magnetite concentrate samples a high grade hematite ore were used as iron oxide source. Two different sodium bentonite samples were used as reference binder to compare the performances of tested binders. The characteristics of the iron oxides and bentonites are given in Table 1.

Table 1. The chemical and physical characteristic of the iron oxides and bentonites.

\begin{tabular}{|c|c|c|c|c|c|c|c|c|c|c|c|c|c|c|c|c|}
\hline \multirow{2}{*}{ Material } & \multirow{2}{*}{ Origin } & \multicolumn{10}{|c|}{ Chemical composition, wt\% on dry basis } & \multicolumn{2}{|c|}{$\begin{array}{c}\text { Particle Size } \\
\mu \mathrm{m}\end{array}$} & \multirow{2}{*}{\begin{tabular}{|c|}
$\begin{array}{c}\text { Blaine } \\
\text { Number }\end{array}$ \\
$\mathrm{cm}^{2} / \mathbf{g}$ \\
\end{tabular}} & \multirow{2}{*}{\begin{tabular}{|c|}
$\begin{array}{c}\text { Specific } \\
\text { Gravity }\end{array}$ \\
- \\
\end{tabular}} & \multirow{2}{*}{$\begin{array}{c}\begin{array}{c}\text { Loss on } \\
\text { Ignition }\end{array} \\
\%\end{array}$} \\
\hline & & $\begin{array}{c}\text { Total } \\
\text { Fe }\end{array}$ & $\mathrm{SiO}_{2}$ & $\mathrm{Al}_{2} \mathrm{O}_{3}$ & $\mathrm{CaO}$ & MgO & $\mathrm{Na}_{2} \mathrm{O}$ & $\mathrm{K}_{2} \mathrm{O}$ & $\mathbf{S}$ & $\mathrm{P}_{\mathbf{2}} \mathrm{O}_{5}$ & $\mathrm{TiO}_{2}$ & $\mathbf{P}_{100}$ & $\mathbf{P}_{80}$ & & & \\
\hline Magnetite 1 & Turkey & 69.25 & 0.95 & 1.01 & 0.53 & 0.90 & 0.05 & 0.14 & 0.48 & $<0.1$ & $<0.01$ & 176 & 61.981 & $1617 \pm 24$ & 5.10 & - \\
\hline Magnetite 2 & USA & 65.52 & 4.87 & 0.09 & 0.44 & 0.37 & $<0.01$ & 0.02 & 0.03 & 0.05 & 0.01 & 62.23 & 27.602 & $2212 \pm 38$ & 4.64 & - \\
\hline Hematite & Brazil & 66.62 & 5.71 & 3.05 & 0.048 & 0.017 & $7<0.11$ & 0.006 & 0.005 & 0.16 & 0.054 & 248.90 & 76.951 & $1891 \pm 35$ & 4.90 & - \\
\hline Bentonite 1 & Turkey & 4.17 & 67.76 & 16.86 & 2.19 & 3.62 & 1.38 & 0.73 & - & - & - & 88.00 & 16.13 & - & - & 2.93 \\
\hline Bentonite 2 & USA & 3.96 & 58.36 & 21.14 & 1.43 & 2.98 & 3.82 & 0.58 & - & - & - & 124.50 & 13.11 & - & - & 6.75 \\
\hline
\end{tabular}

Three common organic binders namely technical grade CMC, food grade corn starch, and dextrin, were tested as alternative binders to bentonite. Three different specialty manufactured OBB namely Ciba@ DPEP06-0007 polymer, Superfloc ${ }^{\circledR}$ A150-LMW flocculant and Superfloc ${ }^{\circledR}$ A150HMW flocculant. were tested as alternative binders. Four different boron compounds (two natural mineral and two derivatives) were tested as binder alone or together with an organic/manufactured organic binder. The boron compounds selected for the study are 
colemanite, tincal, borax pentahydrate and boric acid. Colemanite was used after calcining at $550^{\circ} \mathrm{C}$, the other used as powder. The chemical and physical characteristic of the boron compounds are given in Table 2.

Table 2. The chemical and physical characteristic of the boron compounds.

\begin{tabular}{|c|c|c|c|c|c|c|c|c|c|c|c|c|c|}
\hline \multirow{2}{*}{ Material } & \multirow{2}{*}{ Origin } & \multicolumn{7}{|c|}{ Chemical composition } & \multicolumn{2}{|c|}{$\begin{array}{c}\text { Particle Size } \\
\mu \mathrm{m}\end{array}$} & \multirow{2}{*}{\begin{tabular}{|c|}
$\begin{array}{c}\text { Melting } \\
\text { Point }\end{array}$ \\
${ }^{\circ} \mathrm{C}$
\end{tabular}} & \multirow{2}{*}{$\begin{array}{c}\text { Specifi } \\
\text { c } \\
\text { Gravity } \\
- \\
-\end{array}$} & \multirow{2}{*}{$\begin{array}{c}\begin{array}{c}\text { Residual content } \\
\text { at } 1000^{\circ} \mathrm{C}\end{array} \\
\%\end{array}$} \\
\hline & & $\begin{array}{l}\text { Chemical } \\
\text { Formula }\end{array}$ & $\begin{array}{c}\mathrm{B}_{2} \mathrm{O}_{3} \\
\%\end{array}$ & $\mid \begin{array}{c}\mathrm{SiO}_{2} \\
\%\end{array}$ & $\begin{array}{c}\mathrm{Na}_{2} \mathrm{O} \\
\%\end{array}$ & $\begin{array}{c}\mathrm{CaO} \\
\%\end{array}$ & $\begin{array}{c}\mathrm{SO}_{3} \\
\%\end{array}$ & $\begin{array}{c}\mathrm{As}_{2} \mathrm{O}_{3} \\
\mathrm{ppm}\end{array}$ & $\mathbf{P}_{100}$ & $\mathbf{P}_{80}$ & & & \\
\hline Colemanite & Turkey & $\mathrm{Ca}_{2} \mathrm{~B}_{6} \mathrm{O}_{11} \cdot 5\left(\mathrm{H}_{2} \mathrm{O}\right)$ & 43.00 & $<6.50$ & - & 28.00 & 0.50 & $<50$ & 176.00 & 54.67 & 986 & 1.95 & 97.31 \\
\hline Tincal & Turkey & $\mathrm{Na}_{2} \mathrm{~B}_{4} \mathrm{O}_{7} \cdot 10 \mathrm{H}_{2} \mathrm{O}$ & 36.47 & -1 & 16.24 & - & - & $<50$ & - & - & 62 & 1.71 & - \\
\hline $\begin{array}{c}\text { Borax } \\
\text { pentahydrate }\end{array}$ & Turkey & $\mathrm{Na}_{2} \mathrm{~B}_{4} \mathrm{O}_{7} .5 \mathrm{H}_{2} \mathrm{O}$ & 47.76 & -2 & 21.25 & - & - & $<50$ & - & - & 200 & 1.81 & 67.89 \\
\hline Boric acid & Turkey & $\mathrm{H}_{3} \mathrm{BO}_{3}$ & 56.00 & - & - & - & - & - & - & - & 236 & 1.435 & - \\
\hline
\end{tabular}

\subsection{Pelletizing Experiment Procedure}

The detailed laboratory scale pelletizing procedure was explained elsewhere (Sivrikaya, 2011). The bentonite binders were used to produce reference pellets and the performances of the alternative tested binders on pellet qualities have been compared with those performances of reference pellets bonded with bentonite. Different binder addition dosages (0.25-1.00\%) and thermal treatment temperatures were tested to determine their effects on pellet physicalmechanical qualities.

\subsection{Determination of physical and mechanical pellet properties}

Size and shape of pellets: Industrially, at least $90 \%$ of spherical pellets should be between 9.0 and $16 \mathrm{~mm}$ with minus $5 \mathrm{~mm}$ material of no more than $5 \%$. A close size distribution is preferred for a better permeability of the pellet bed in the firing machine in industry. Hence, the pellets were produced in spherical shape in $-12.7+11.2 \mathrm{~mm}$ diameter during laboratory pelletizing experiment.

Moisture content: Wet pellets should have optimum moisture for better balling in drum or disc. Balling and agglomeration cannot be carried out while the excessive moisture content and low moisture causes the fragile wet pellets. The optimum moisture lies between $8-10 \%$ depending of some properties of concentrate. During wet pellet production the moisture content was tried to keep constant at around $10 \%$. After producing wet pellets in laboratory balling drum or disc, wet pellets were put in a laboratory oven to dry them at $105^{\circ} \mathrm{C}$. The moisture content was calculated by wet and dry weight difference of wet and dry pellets.

Drop number: Number of the repeated drop of 9-16 mm wet pellets onto a steel plate from a height of $46 \mathrm{~cm}$ without any cracks on the wet pellets is defined as drop number. Drop number measures the ability of the wet pellets to retain their shape during transfer operations. An industrial pellet should withstand at least 4 drops. Wet pellets were used to determine the wet pellet drop number by dropping a single wet pellet repeatedly from a height of $46 \mathrm{~cm}$ onto a steel plate. 
Compressive strengths: Compressive strengths of wet and thermally treated pellets at different temperatures from $100-1300^{\circ} \mathrm{C}$ was determined in accord with the method described in the related standard (ASTM E 382-07).

Wet Compressive Strength: Wet pellets on conveyors and grates should withstand a certain load. Wet compressive strength is a measure of how much load a wet pellet can bear and determined by applying pressure onto a wet pellet until it cracks and the maximum load is recorded. It should ideally be greater than $1.0 \mathrm{~kg} / \mathrm{pellet}$ industrially.

Dry Compressive Strength: In travelling grate minimum dry pellet strength is necessary so that the pellets withstand the load of pellet layers located above or the pressure of gases flowing through the charge (Meyer, 1980). A dried pellet is crushed and the maximum load is recorded. It measures the ability of dried pellets to survive handling during the firing process. Should be a mean value at least $2.2 \mathrm{~kg} /$ pellet industrially (Kawatra and Ripke, 2002).

Pre-Heated Pellet Strength: Especially, when pellets are produced with the travelling graterotary kiln-cooler technology, they are preheated in the travelling grate prior to firing in the kiln. The preheated pellets from the grate are discharged by cascading into the kiln. Therefore, such pellets should be strong enough not to disintegrate during cascading and tumbling in the rotary kiln. In the case of weak pellets, dust and chips generated as a result of disintegration will cause losses in plant efficiency, in terms of both productivity and quality.

Fired Compressive Strength: Fired pellet is crushed under pressure and the maximum load is recorded. It measures the ability of product pellets to survive handling during shipment and reduction. Pellets should have a mean product pellet compressive strength value of minimum 250 $\mathrm{kg} /$ pellet with the $<150 \mathrm{~kg} /$ pellet fraction less than $5 \%$ industrially.

Porosity: Porosity of typical industrial wet and dry pellets should be in the range of 31 - $36 \%$ whilst it should be 18 - 32\% for fired pellets. Porosities of the dry and thermally treated pellets was determined according to method which is based on the measurement of the real specific gravity and apparent specific gravity of the pellets.

Dustiness: The dust generation potential of fired pellets at $1200^{\circ} \mathrm{C}$ was determined with a novel dust tower apparatus. Dust Tower was designed to capture all of the airborne dust, during dropping of fired pellets through from 11 inclined steel plates, onto a filter paper where it could be weighed. The detailed dustiness experiment was explained, elsewhere (Copeland and Kawatra, 2005, Sivrikaya and Arol, 2013).

\section{RESULTS AND DISCUSSION}

Some of the organic binders and boron compounds were found insufficient to provide sufficient physical-mechanical pellet qualities alone. All results were presented in the Ph.D. dissertation by Sivrikaya, 2011, some selected results were presented below. The mean values of 20 randomly pellet samples were given with the $95 \%$ confidence level (P95) in the graphs.

\subsection{Moisture content and drop number of wet pellets}

Wet pellet moisture content (WPMC): WPMCs varied from 8.38 to $10.22 \%$ (Figure 1). The smallest WPMC was found to be $8.38 \%$ for the pellets produced without binder. The WPMCs of 
pellets made with bentonite samples are $8.53 \%$ and $8.44 \%$. The WPMC produced with only calcined colemanite (CC) is 8.52 -about the same as bentonite bonded pellets. However, the WPMCs are greater for the organic binders-bonded pellets. The value increased up to $10.22 \%$ for the pellets produced with CMC plus CC addition. The water absorption capacity of the OBB is the reason behind the relatively great WPMCs obtained with organic binder addition.

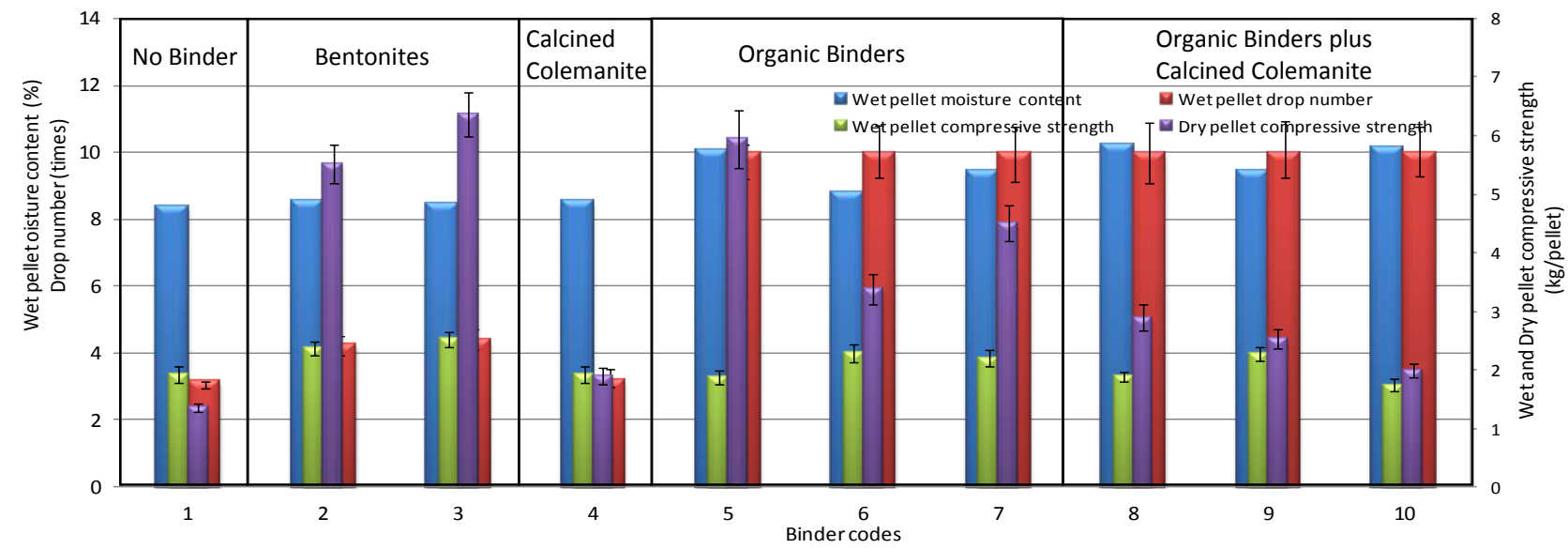

Figure 1. Moisture content, drop number, compressive strengths of wet and dry magnetite pellets (bentonite, CC dosage:0.66\% and organic binders dosage:0.10\%)

Wet pellet drop numbers (WPDN): The WPDNs obtained by using reference bentonite binders was found to be 4.27 and 4.40 , which are slightly over the limit so they are sufficient. However, WPDN values for pellets made without binder and with only CC addition were determined to be 3.17 and 3.21, respectively, which are a little lower than the required value. Therefore, they can be considered insufficient and the production of pellets without binder or only with CC addition seems impossible in terms of sufficient WPDN. The WPDNs produced with organic binders were found sufficient $(>10.00)$.

\subsection{Compressive strengths of wet, dry and thermally treated pellets}

Wet pellet compressive strengths (WPCS): WPCS values obtained with alternative organic binders alone and in combination with CC are given in Figure 1. The compressive strength of wet pellets produced in industry usually lies between 1.0 and $2.0 \mathrm{~kg}$ (Ball, et al., 1973). Therefore, WPCS should be greater than $1 \mathrm{~kg} / \mathrm{p}$ to meet this specification. All WPCS of pellets were found to be greater than this required limit value. The sufficient WPCS is due to controlling of the wet strength mainly by the viscous forces of liquid binder water.

Dry pellet compressive strengths (DPCS): DPCS are given in Figure 1 as well. In the drying process, a minimum dry strength of $2.2 \mathrm{~kg}$ is essential in the critical phase of drying when the weight of bed of pellets is supported by the-just dry pellets (Ball, et al., 1973). Hence, DPCS should be, at minimum, $2.2 \mathrm{~kg} / \mathrm{p}$ to withstand weight of the pellet bed. The DPCSs were found between 1.35 and $6.37 \mathrm{~kg} / \mathrm{p}$. The insufficient DPCS values were found when only CC used as binder. However, the insufficient DPCS values were recovered when an organic binder used together with CC. 
Thermally treated pellet compressive strengths: Thermally treated magnetite pellet compressive strengths are given in Figure 2 . The increasing temperature increased the compressive strength of pellets. The compressive strengths of preheated pellets at $1000^{\circ} \mathrm{C}$ made with organic binders can be improved with the addition of colemanite. The effect of colemanite addition on the pellet strength increase is more pronounced at $1100^{\circ} \mathrm{C}$. The strengths of pellets with colemanite addition are significantly greater than the bentonite bonded reference pellets. These strengths are sufficient since the minimum industrially required strength for product pellets is $250 \mathrm{~kg} / \mathrm{p}$ (Ball, et al., 1973). Firing temperature of iron oxides is generally $1250-1350^{\circ} \mathrm{C}$ depending on the genesis of iron oxides. The industrially sufficient compressive strength was obtained for the pellets fired at $1100^{\circ} \mathrm{C}$ with the addition of $0.66 \%$ colemanite. This result shows that in the presence of colemanite in pellet feed, the lower firing temperature is enough to get industrially sufficient strength. This means if colemanite is added in pellet mixture, the energy consumption can be lowered by lowering firing temperature. Especially, the contribution of addition of boron compound is most pronounced for hematite ore pellets which do not have strengthening mechanism through oxidation like magnetite ores during firing (Table 3 ).

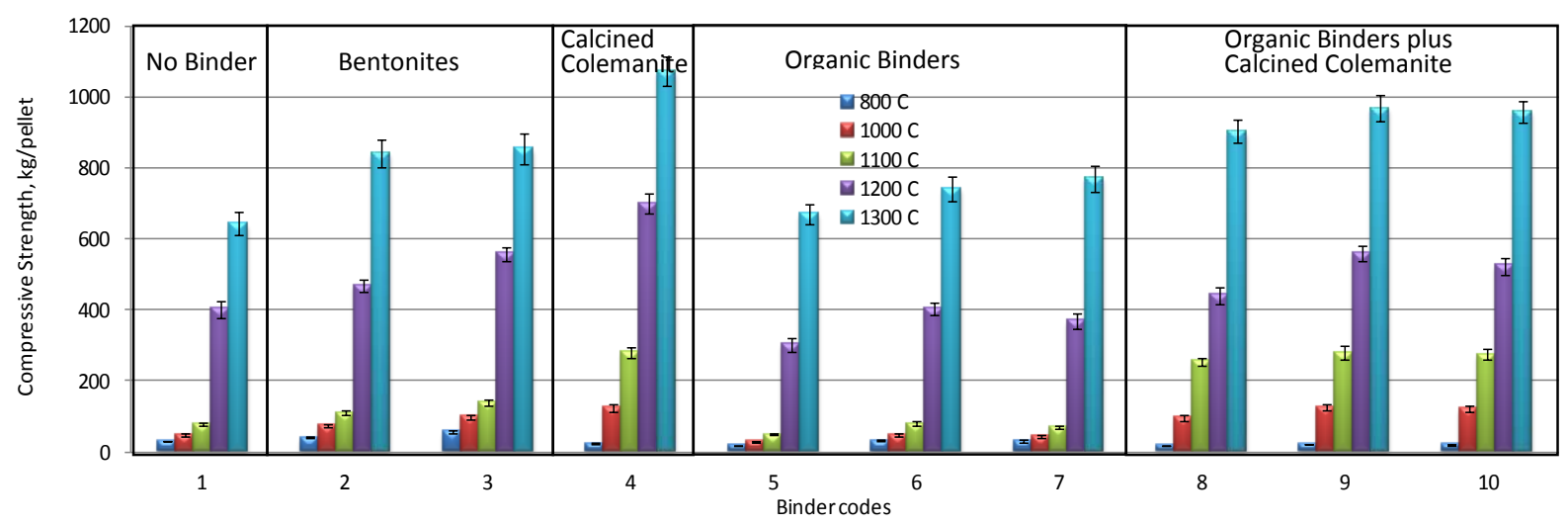

Figure 2. Thermally treated magnetite pellet compressive strengths (bentonite, CC dosage:0.66\% and organic binders dosage:0.10\%)

Table 3. Preheated and fired hematite pellet compressive strengths (kg/pellet)

\begin{tabular}{|c|c|c|}
\hline Binders and dosages & $\begin{array}{l}\text { Preheated strength at } \\
1000^{\circ} \mathrm{C}\end{array}$ & $\begin{array}{l}\text { Fired strength at } \\
1300^{\circ} \mathrm{C}\end{array}$ \\
\hline Bentonite $0.50 \%$ (reference pellets) & $49.60 \pm 5.63$ & $381.10 \pm 42.25$ \\
\hline Calcined Colemanite $0.25 \%+$ & $83.90 \pm 7.49$ & $478.90 \pm 44.70$ \\
\hline Calcined Colemanite $0.50 \%+$ & $116.10 \pm 5.71$ & $602.00 \pm 54.80$ \\
\hline Calcined Colemanite $0.75 \%+$ & $151.40 \pm 22.80$ & $772.00 \pm 95.37$ \\
\hline Calcined Colemanite $1.00 \%+$ & $219.30 \pm 18.11$ & $893.60 \pm 76.80$ \\
\hline CMC $0.10 \%$ + Calcined Colemanite $0.50 \%$ & $121.00 \pm 10.37$ & $535.10 \pm 48.68$ \\
\hline CMC $0.10 \%+$ Calcined Colemanite $1.00 \%$ & $199.80 \pm 21.127$ & $841.10 \pm 77.10$ \\
\hline Corn starch $0.10 \%+$ Calcined Colemanite $0.50 \%$ & $118.20 \pm 5.61$ & $512.20 \pm 68.03$ \\
\hline Corn starch $0.10 \%+$ Calcined Colemanite $1.00 \%$ & $217.80 \pm 16.71$ & $736.90 \pm 86.57$ \\
\hline $\begin{array}{l}\text { DPEP06-007 Polymer } 0.10 \%+\text { Calcined Colemanite } \\
0.50 \%\end{array}$ & $127.50 \pm 11.98$ & $457.70 \pm 51.86$ \\
\hline $\begin{array}{l}\text { DPEP06-007 Polymer } 0.10 \%+\text { Calcined Colemanite } \\
1.00 \%\end{array}$ & $173.80 \pm 14.25$ & $789.70 \pm 86.88$ \\
\hline
\end{tabular}

\subsection{Porosity of pellets}

Porosities of pellets produced with different binders and thermally treated at 105-800$1000-1100-1200$ and $1300^{\circ} \mathrm{C}$ were determined to see the effects of different binders and heating 
temperatures on porosity of pellets (Figure 3). With increasing temperature, the porosity decreases for all pellets. The porosities were determined to be about $18-21 \%$ for pellets fired at $1300^{\circ} \mathrm{C}$. The porosity differences between pellets contain OBB and bentonite or CC is only about $2-3 \%$. The product pellets fired at $1200^{\circ} \mathrm{C}$ have the highest porosity about $25 \%$ was obtained for pellets produced with $\mathrm{OBB}$. If pellets contain bentonite or $\mathrm{CC}$, this time porosity will be around 22$23 \%$ at the same temperature. In literature, typical porosities for wet and dry pellets from high grade iron oxide are mentioned in the range $31-36 \%$, whilst a porosity of $22-30 \%$ for fired pellets is associated with good reducibility (Ball et al., 1973). The porosities for pellets produced with different binder addition were found in the industrial pellet porosity percentage interval.

\subsection{Dustiness of pellets}

Relationship between dust generation and compressive strength of magnetite pellets produced with different binders and fired at $1200^{\circ} \mathrm{C}$ were shown below in Figure 4 . It can be seen from this Figure that the compressive strengths of pellets bonded with OBB are lower than those of bentonite bonded or CC bonded pellets. They are even lower than those pellets produced without binder. OBB lead more porous pellet structure since they are decomposed and volatilized with fewer residues at such elevated temperatures. The low compressive strength of those pellets would be due to the high porosity generated by the decomposition of OBB and bad crystallized status in this firing condition. As a result the presence of $O B B$ in pellet mixture decreased the compressive strengths of sintered pellets. On the other hand, the presence of CC has increased the compressive strengths of pellets due to the low melting point of CC. The high compressive strength of pellets bonded with colemanite is due to the bonding effect of melted CC between the magnetite mineral grains. The results of dust measurement tests of those pellets showed that OBB and CC addition into the pellets can decrease the dust emission of pellets. As much as $50 \%$ of the dust can be decreased by using OBB and CC combination instead of bentonite.

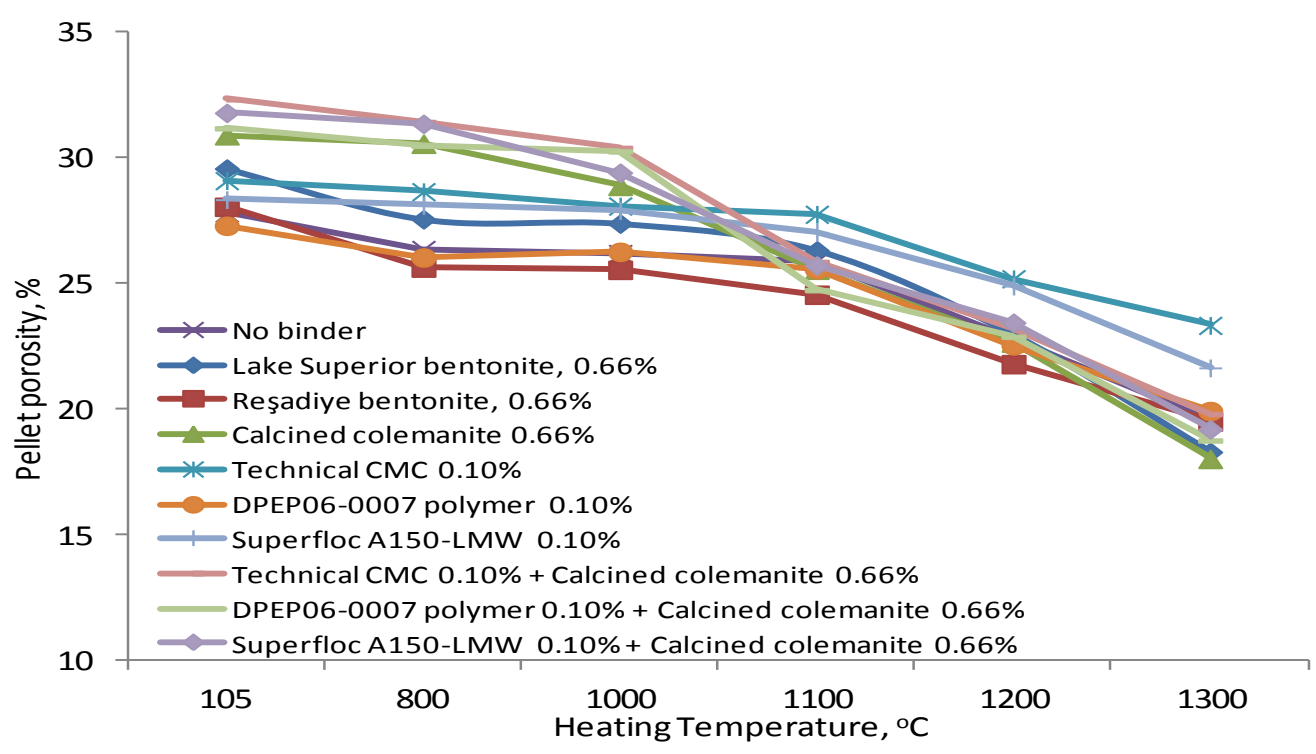

Figure 3. Porosity of magnetite pellets 


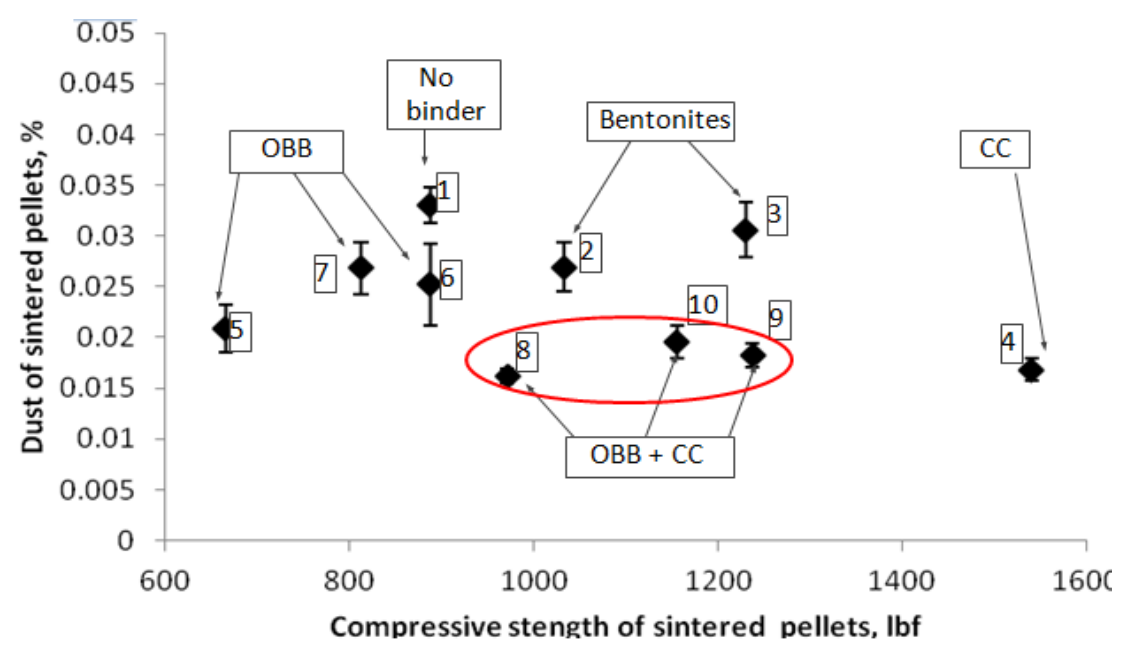

Figure 4. Relationship between dust generation and cmpressive strength of magnetite pellets (bentonite, calcined colemanite dosage: $0.66 \%$ and organic binders dosage: $0.10 \%$ ).

\section{CONCLUSION}

In the present study, the addition of boron compounds into pellet mixture was proposed to increase the low pellet compressive strength encountered with use of organic binders in iron ore pelletizing. The performances organic binders and boron compounds alone and in combination on physical-mechanical pellet qualities were comparatively tested against bentonite binder performance. The results showed that while organic binders provided sufficient wet and dry pellet physical strengths, the boron compounds rendered the required preheated and fired pellet strengths at even lower firing temperature like $1100^{\circ} \mathrm{C}$. Especially, the contribution of addition of boron compound is most pronounced for hematite ores pellets which do not have strengthening mechanism through oxidation like magnetite ores during firing. Therefore, addition of a boron compounds thanks to melting characteristic and slag bonding is beneficial to recover the low physical and mechanical qualities of pellets produced with organic binders. Furthermore, lowering the firing temperature by means of low-melting boron compounds will be cost-effective for firing part of the pelletizing plants.

\section{REFERENCES}

1. ARORA, M.L., BARTH, E., UMPHRES, M.B. Technology evaluation of sequencing batch reactors. Journal Water Pollution Control Federation, v.57, n.8, p. 867-875, ago. 1985.

2. AKBERDIN A. and KIM A.S., "Production and blast-furnace smelting of boron-alloyed iron-ore pellets", Steel in Translation, Vol. 38, No. 8, pp.625-629. (C) Allerton Press, Inc., 2008. Original Russian Text (C) A.A. Akberdin, A.S. Kim, published in "Stal" No. 8, pp. 10-14, 2008.

3. ASTM E 382-07 "Standard test method for determination of crushing strength of iron ore pellets".

4. BALL D. F., DARTNELL J., DAVISON J., GRIEVE A., WILD R., "Agglomeration of iron ores", American Elsevier Publishing company, Inc., New York, 1973.

5. COPELAND C. R. and KAWATRA S. K., "Dust Suppression in iron ore processing plant", Minerals \& Metallurgical Processing, 22, 4, Nov 2005, pp. 177. 
6. EISELE T. C. and KAWATRA S. K., "A review of binders in iron ore pelletization", Mineral Processing \& Extractive Metallurgy Rev., Vol. 24: pp. 1-90, 2003.

7. GOETZMAN, H.E., BLEIFUSS, R.L. and ENGESSER, J., "Investigation of carboxymethyl cellulose binders for taconite pelletizing," In: SME Annual Meeting, Phoenix, AZ, USA, 1988, pp. 88-111.

8. KATER, T., and STEEGHS, H.R.G., "Organic binders for iron ore pelletization", In: 57th Annual Meeting of the Minnesota Section of AIME, Duluth-MN, USA, pp.13.1-13.29, 1984.

9. KAWATRA S.K. and RIPKE S.J., "Pelletizing steel mill desulfurization slag", Int. J. Miner. Process., vol. 65, pp. 165-175, 2002.

10. KÖROĞLU M. N., "Use of calcined colemanite and bentonite as binders in the pelletizing of Hasan Çelebi iron ore", M.Sc. Thesis, Middle East Technical University, Ankara, Turkey, 1980.

11. MALYSHEVA T.Ya., CHESNOKOVA G.V., AKBERDIN A.A. and DOLITSKAYA O.A., "Effect of Boron on the Quality of Iron Ore Pellets", Izvestiya Possiskoi Akadaemii Nauk. Metally, No. 1, pp. 37, 1996.

12. MEYER K., "Pelletizing of iron ores", Springer-Verlag Berlin Heidelberg New York Verlag Stahleisen $\mathrm{GmbH}$, Düsseldorf, 1980.

13. RIPKE, S.J. and KAWATRA, S.K., "Can fly-ash extend bentonite binder for iron ore agglomeration?" International Journal of Mineral Processing, Vol.60, Issues.3-4 Elsevier, Amsterdam, pp. 181-198, December 2000.

14. SCHMITT J., "A Method for Improving the Process and Quality of Iron Ore Pellets Made with Organic Binders", in 66th Annual University of Minnesota Mining Symposium, April 19-20, Duluth, MN, USA, 2005.

15. SIVRIKAYA O., "Use of boron based binders in pelletization of iron ores: Alternative binders to bentonite for iron ore pelletization" LAP LAMBERT Academic Publishing, GmbH \& Co. KG, Saarbrucken, Germany, ISBN-13: 978-3845475653, p. 260, 2011.

16. SIVRIKAYA, O., AROL A. I., "Investigation of the dust generation mechanism of sintered magnetite pellets by a novel dust tower" in proceedings of 142nd SME Annual Meeting and Exhibit and CMA 115th National Western Mining Conference, Denver, Colorado, USA, 24- 27 Feb 2013.

17. TIMUÇIN M., GEVECI A., SEVINÇ N., TOPKAYA Y. and ERIÇ H., "The use of colemanite in steel production", Middle East Technical University Project No:84-04-07-00-13, pp. 100-111, 1986. 